\section{Tempos de}

racialização: 0 caso da 'saúde da população negra' no Brasil

\author{
In times of
}

racialization: the case of the 'health of the black population' in Brazil
MAIO, M. C.; MONTEIRO, S.: Tempos de racialização: o caso da 'saúde da população negra' no Brasil.

História, Ciências, Saúde - Manguinhos, v. 12, n. 2, p. 419-46, maio-ago. 2005.

Este artigo tem por objetivo analisar as iniciativas para a criação de um campo de reflexão e intervenção política denominado 'saúde da população negra', no período entre 1996 e 2004, que contempla o governo FHC e parte da administração de Lula. A discussão e implementação de políticas de ação afirmativa no Brasil adquire maior visibilidade, especialmente após a $3^{\mathrm{a}}$ Conferência Mundial contra o Racismo, Discriminação Racial, Xenofobia e Formas Correlatas de Intolerância, sob os auspícios da ONU (Durban, África do Sul, 2001). O artigo descreve a emergência de uma proposta de política compensatória. Em seguida, aborda o debate contemporâneo sobre raça e saúde, sobretudo a literatura biomédica norteamericana, à luz das apropriações dessa discussão por agências e agentes comprometidos com a formulação de uma 'política racial' no âmbito da saúde pública no Brasil.

PALAVRAS-CHAVE: raça; racismo; saúde pública no Brasil; Conferência de Durban; movimento negro.

MAIO, M. C.; MONTEIRO, S.: In times of racialization: the case of the 'health of the black population' in Brazil.

História, Ciências, Saúde - Manguinhos, v. 12, n. 2, p. 419-46, May-Aug. 2005.

The article analyzes initiatives aimed at creating a field of reflection and political intervention called the 'health of the black population,' which occurred between 1996 and 2004, that is, under the administration of Fernando Henrique Cardoso and part of Luis Inácio Lula da Silva's administration. During this period, the process of discussing and enacting affirmative action policies in Brazil gained greater visibility, especially following the UN-sponsored Third World Conference on Racism, Racial Discrimination, Xenophobia, and Related Intolerance (Durban, South Africa, September 2001). The article describes the emergence of a proposal of compensatory policy within the Brazilian public health system. It then addresses the contemporary debate on race and health, especially the U.S. biomedical literature, and explores how this discussion has been appropriated by agencies and agents concerned with drawing up a 'racial policy' for the public health sector in Brazil.

KEYWORDS: racism; race; public health in Brazil; affirmative action policies; Durban conference; black movement. 


\section{Introdução}

E $\mathrm{m}$ anos recentes, as relações entre raça e saúde vêm sendo objeto de uma série de iniciativas centrada na criação de um campo de reflexão e de intervenção política denominado 'saúde da população negra'. ${ }^{1}$ Essa proposta se insere na discussão sobre formas de enfrentamento do racismo no país, na medida em que governo, intelectuais e parcelas significativas da sociedade civil reconhecem atualmente as desvantagens materiais e simbólicas sofridas pelos negros. Apesar de não haver consenso quanto aos diagnósticos e às soluções para o problema da discriminação racial, ele adquire maior visibilidade em função do atual debate sobre os temas da pobreza e da justiça social. Nesse cenário, 'raça' emerge não apenas como uma ferramenta analítica para tornar inteligíveis os mecanismos estruturais das desigualdades sociais, mas também como instrumento político para a superação das iniqüidades históricas existentes no Brasil.

As interfaces entre raça, medicina e saúde pública estiveram em voga entre as últimas décadas do século XIX e os anos 40 do século XX, enquanto fontes inspiradoras de políticas públicas. Desde o fim da escravidão e o advento do regime republicano, elites dirigentes e intelectuais se depararam com o desafio de repensar a nação e as suas possibilidades de adentrar o mundo moderno com uma população composta por brancos, mestiços e negros. A título de ilustração, as medidas tomadas pelo governo brasileiro para debelar os surtos epidêmicos de febre amarela, entre fins do século XIX e início do XX, são interpretadas por parte da historiografia como componentes de um período em que as políticas sanitárias privilegiaram a proteção aos europeus recém-chegados. Esse contingente, supostamente civilizado, acometido em grande escala pela doença, viria a assegurar, conforme a 'política racial' calcada na ideologia do branqueamento, uma nova composição demográfica da população brasileira rumo à modernidade (Chalhoub, 1996; Maio, 2004).

Nas primeiras décadas do século XX houve uma disputa entre diferentes projetos de nação, ancorados, em graus variados, no conhecimento médico e sanitário da época. Grosso modo, pode-se dividir esse momento em duas vertentes interpretativas. A primeira delas atribui ao conceito de raça papel demiúrgico no processo de compreensão e intervenção na dinâmica societária, inspirada numa visão determinista biológica e mantendo vínculos estreitos com a antropologia física oitocentista. Essa corrente teve forte ascendência no campo da medicina legal, particularmente nos trabalhos do 'médico-antropólogo' Nina Rodrigues. A sua produção intelectual teve significativa influência nas críticas ao liberalismo da Primeira República, na modernização do aparato policial, especialmente nos pro- 
cessos de controle e identificação das 'classes perigosas' e, não menos relevante, nos estudos sobre o negro (Corrêa, 1998; Schwarcz, 1993).

A segunda vertente, inspirada na tradição médico-higienista, alcançou maior proeminência durante a Primeira Guerra Mundial. O pensamento nacionalista vigente, somado aos avanços da bacteriologia e da microbiologia, considerou que expressiva parcela da população pobre atingida por doenças infecto-contagiosas, localizada principalmente no interior do país, "não era assim, estava assim", lembrando a autocrítica de Monteiro Lobato na famosa análise do seu personagem Jeca Tatu. Essa a era dos sanitaristas. Os seus temas eram: expansão do aparato estatal; incorporação social de populações marginalizadas; centralização das políticas de saúde pública; e visão crítica em relação aos reducionismos climático e racial (Lima \& Hochman, 1996). A perspectiva sanitarista exerceu papel central no processo de inflexão de interpretações racialistas para argumentos sociológicos e culturalistas ainda nos anos 20 . Mesmo no caso da 'eugenia à brasileira', entre as décadas de 1920 e 1940, diferente do modelo determinista anglo-saxão, prevaleceu a interpretação que atribuía ao saneamento, à higiene e à educação as melhores alternativas para a superação do atraso econômico e social (Stepan, 1991, p. 118-9).

Com o fim da Segunda Guerra Mundial e da ditadura estadonovista, quando se inaugurou a experiência democrática de 19461964, o otimismo sanitário internacional no combate às doenças endêmicas em áreas periféricas foi acompanhado pela concepção, inspirada no binômio saúde e desenvolvimento, que atravessou os anos 50 e 60, de que os agravos à saúde eram impeditivos à modernização do Brasil (Lima, 2002). Nesse período, diversas iniciativas foram deslanchadas na direção da ampliação do acesso da população aos serviços de saúde em consonância com as reformas sociais em curso. O golpe militar de 1964 impediu que esse processo fosse expandido. O novo regime, autoritário e centralizador, empreendeu um amplo processo de privatização da saúde pública (Lima et al., 2005; Arretche, 2005). Na década de 1980, mediante a atuação do movimento da Reforma Sanitária, legitima-se no plano constitucional o projeto de universalização do acesso à saúde, corporificado no Sistema Único de Saúde (SUS) em contexto de democratização do país (Escorel, 1999; Gershman, 1995; Viana, 2001).

Cabe registrar que a tradição sanitarista brasileira continuou a não atribuir importância à temática racial. ${ }^{2}$ Só no alvorecer do século XXI voltam à cena pública as relações entre raça e saúde, a partir da proposta de criação de uma política focal direcionada à população negra. Esta se baseia na concepção de que as desigualdades raciais repercutem de forma específica na esfera da saúde pública e, por conseguinte, devem ser objeto de ação governamental para superá-las. Com base numa articulação que envolve ONGs 
vinculadas ao movimento negro, agências estatais, fundações filantrópicas norte-americanas, instituições multilaterais e fóruns internacionais, especialmente no plano dos Direitos Humanos, a nova política anti-racista surge no contexto da discussão sobre políticas de ação afirmativa no Brasil, iniciada nos anos 90.

A constituição do domínio da 'saúde da população negra' vem privilegiando o fortalecimento de identidades primordiais. De acordo com Guimarães: "para os afro-brasileiros, para aqueles que se chamam a si mesmos de 'negros', o anti-racismo deve significar, antes de tudo, a admissão de sua 'raça', isto é, a percepção racializada de si mesmo e do outro" (1999, p. 58). É apenas a partir da afirmação de uma identidade racial, mediante a polarização branco/negro, que se forja a 'consciência racial', pré-condição para a luta contra as iniqüidades. Essa dinâmica tem no Estado um ator central na medida em que a adoção de políticas de ação afirmativa exige a definição de um foco preciso para os seus beneficiários ('sujeitos raciais'). Num país como o Brasil, em que os cidadãos são pouco afeitos a sistemas rígidos de classificação racial, a atuação estatal vem se revelando indispensável à produção da 'raça negra' (Fry, 2005; Grin, 2001).

Essa dinâmica ocorre simultaneamente à redução do papel do Estado no plano econômico e social na era global, com conseqüências negativas visíveis ao mundo dos direitos sociais. Ademais, o clássico conceito de cidadania, com base nos princípios da universalidade e da igualdade, é colocado em xeque pela perspectiva multiculturalista. Ela sugere uma 'cidadania cultural' em nome do reconhecimento de atores políticos e, em especial, de movimentos sociais que procuram assumir a representação de grupos historicamente injustiçados. Tudo isso toca em pontos sensíveis da complexa relação entre raça e saúde, seja pela inconsistência do conceito de raça, como insistem em afirmar os geneticistas, seja pelas interrelações entre raça e agravos à saúde, ainda mais quando essas interfaces vêm se tornando objeto de política do Estado em tempos de racialização. ${ }^{3}$

É com base nesse conjunto de temas que este artigo visa descrever o processo de construção de uma política compensatória entre 1995 e 2004 . O recorte temporal compreende desde as primeiras iniciativas do governo Fernando Henrique Cardoso (1994-2002) até o 1ำ Seminário Nacional de Saúde da População Negra, realizado em agosto de 2004, sob a gestão do presidente Luiz Inácio Lula da Silva, quando foi instalado o Comitê Técnico de Saúde da População Negra do Ministério da Saúde. O trabalho aborda, em princípio, a emergência da 'saúde da população negra', as inflexões ocorridas nesse processo e a correspondente agenda política. Em seguida, analisa conteúdos programáticos presentes em documentos produzidos no âmbito do Ministério da Saúde, em parceria com a Secretaria Especial de Políticas de Promoção da Igualdade Racial 
(Seppir), com base na discussão contemporânea sobre raça e saúde, sobretudo a literatura biomédica norte-americana. Por fim, fazse um balanço dos esforços envidados para a criação de uma "política racial", conforme expressão de Martins (2004, p. 58), no campo da saúde pública.

\section{FHC e os primórdios do debate sobre 'saúde da população negra'}

A proposta de uma política com recorte racial na área da saúde pública no Brasil só ganhou visibilidade no governo Fernando Henrique Cardoso (1994-2002) e principalmente após a 3a Conferência Mundial contra o Racismo, Discriminação Racial, Xenofobia e Formas Correlatas de Intolerância, sob os auspícios da ONU, realizada em Durban, África do Sul (2001).

Cabe, no entanto, lembrar que algumas iniciativas do movimento feminista e, em particular, de lideranças negras foram desenvolvidas, a partir da década de 1980, com o objetivo de ressaltar especificidades raciais no âmbito da saúde reprodutiva. Essas ações, de alcance limitado no contexto nacional, foram influenciadas pela produção intelectual feminista e pelo ativismo negro norte-americanos, que passaram da perspectiva universalista à diferencialista, que atribui centralidade à questão das relações raciais e do racismo (Pierucci, 1999, cap. 5).

Os fóruns nacionais e internacionais das décadas de 1980 e 1990, por sua vez, em sintonia com a reflexão anglo-saxã (Azerêdo, 1994), sedimentaram gradativamente a recusa à perspectiva dominante do 'ser feminino universal', ao incorporarem as variáveis raça e classe, entrelaçadas à de gênero, para a inteligibilidade das desigualdades sociais (Carneiro \& Santos, 1985; Caldwell, 2000).

Um dos temas concernentes às relações entre saúde da mulher e raça que suscitou debate público no país e repercutiu no campo acadêmico foi a existência de um programa de esterilização em massa no Brasil. Embora não haja consenso na literatura sobre o caráter racial da esterilização realizada no país (Berquó, 1994; Caetano, 2004), setores do movimento negro apontaram a existência de um projeto eugênico em curso nas últimas décadas do século $X X$, tendo como alvo central as mulheres negras. Foram criadas Comissões Parlamentares de Inquérito em alguns estados e no Congresso Nacional sobre processos de esterilização (Caetano, 2004). O episódio tornou mais evidente a interface entre o ativismo das mulheres negras e o tema da saúde sexual e reprodutiva. Este tópico, segundo Ribeiro (1995) e Roland (2001a), ganhou nova dimensão em face de uma série de iniciativas (encontros, congressos, fóruns, inserção de militantes em aparatos estatais, construção de redes transnacionais). Vale destacar ainda a V Conferência Mundial de 
População e Desenvolvimento (Cairo, 1994) e a IV Conferência Mundial sobre a Mulher (Beijing, 1995). Ademais, o trabalho desenvolvido por ONGs vinculadas ao movimento negro contou com a colaboração de instituições acadêmicas brasileiras (Nepo/Unicamp e Cebrap) e instituições filantrópicas norte-americanas, a exemplo das Fundações Ford e MacArthur, no apoio a projetos e bolsas que associassem pesquisa acadêmica e intervenção social. Esses são alguns dos marcos que contribuíram para a criação de um 'feminismo negro' (Roland, 2001b).

Monteiro (2004) aponta que nas publicações sobre a 'saúde da população negra', produzidas em sua maioria por ativistas, predomina o argumento segundo o qual a invisibilidade do recorte étnico-racial nas pesquisas da área da saúde pública decorre do não-reconhecimento da existência do racismo na sociedade brasileira. Conforme Batista e Kalckmann (2005, p. 21), haveria uma espécie de aliança entre gestores do sistema de saúde e produção acadêmica para ofuscar a 'saúde da população negra', ao reiterar as chaves explicativas sociológicas que reduziriam o racismo às disparidades socioeconômicas. Com isso, as evidências dos males à saúde atribuídas apenas à pobreza seriam equivocadas, configurando-se como mais uma variante do mito da democracia racial.

Para se contrapor à visão tradicional a-racialista brasileira, diversos artigos, sobretudo de intelectuais negras, procuraram demonstrar a importância da variável raça na prevalência entre a população feminina negra de diabetes tipo II, miomas, hipertensão arterial e anemia falciforme, que podem promover abortamento espontâneo e maior suscetibilidade a infecções, entre outros problemas. Além disso, discutiram os efeitos do racismo na produção das desigualdades em saúde, salienta-se a importância da identificação dos determinantes genéticos e/ou socioeconômicos das doenças étnico-raciais. ${ }^{4}$

Com efeito, só a partir do debate sobre políticas de ação afirmativa no governo Fernando Henrique Cardoso incluiu-se um capítulo relativo à 'saúde da população negra', quando da criação do Grupo de Trabalho Interministerial Para a Valorização e Promoção da População Negra, por decreto presidencial no dia 20 de novembro de 1995, ocasião de uma homenagem aos 300 anos de Zumbi dos Palmares. Essa iniciativa veio no bojo da elaboração do Programa Nacional de Direitos Humanos (PNDC) do governo federal, lançado em 1996. Embora o ativismo negro se considere protagonista do novo cenário, derivado da longa, progressiva e contínua mobilização na luta contra o racismo, é importante assinalar a chegada ao poder de um sociólogo que iniciou sua carreira com uma tese de doutorado sobre as relações entre capitalismo e escravidão sob a orientação de Florestan Fernandes (Cardoso, 1962). Fernando Henrique Cardoso fez parte da segunda geração do 
"projeto Unesco de relações raciais", um ciclo de pesquisas desenvolvido nos anos 1950 e que se tornou um marco nos estudos sobre o 'racismo à brasileira' (Maio, 1999). Não por acaso, ele foi o primeiro presidente da República a reconhecer oficialmente a existência de discriminação racial no país.

Em junho de 1996, no Palácio do Planalto, o Ministério da Justi-ça, com o apoio do Itamaraty, promoveu o seminário internacional "Multiculturalismo e Racismo: o Papel da 'Ação Afirmativa' nos Estados Democráticos Contemporâneos", com a presença de acadêmicos brasileiros e norte-americanos e lideranças do movimento negro, com o intuito de colher subsídios para a formulação de políticas voltadas para a população negra (Souza, 1997; Grin, 2001).

Foi nesse ambiente de discussão sobre ações afirmativas que ocorreu ainda no primeiro semestre de 1996 a "Mesa Redonda sobre a Saúde da População Negra", com a presença de "cientistas, militantes da sociedade civil, médicos e técnicos do Ministério da Saúde". A reunião realizada em Brasília gerou um documento sobre o tema, dividido em quatro itens principais.

O primeiro deles refere-se ao conjunto de "doenças geneticamente determinadas". Elas são classificadas como de "berço hereditário, ancestral e étnico" e os exemplos são: anemia falciforme, considerada a mais importante doença genética que acomete os 'afro-descendentes', seguida pela "hipertensão arterial, o diabete mellitus e uma forma de deficiência de enzima hepática, a glicose-6-fosfato desidrogenase". Pondera-se que esses agravos à saúde recaem sobre outros grupos étnico-raciais, mas que a intensidade de seus efeitos incide especialmente sobre pretos e pardos.

O segundo grupo de doenças diz respeito às adversas condições socioeconômicas, educacionais e psíquicas, tais como: "alcoolismo, toxicomania, desnutrição, mortalidade infantil elevada, abortos sépticos, anemia ferropriva, DST/Aids, doenças do trabalho e transtornos mentais".

O terceiro bloco de males à saúde é formado por uma combinação de determinantes genéticos com desfavoráveis condições sociais de vida, até mesmo no plano cultural, a saber: "hipertensão arterial, diabete mellitus, coronariopatias, insuficiência renal crônica, cânceres e miomas". Mais uma vez se alerta que não obstante essas doenças acometerem a sociedade como um todo, elas seriam mais acentuadas entre a população negra em função da situação desprivilegiada que desfruta na sociedade.

O quarto e último agrupamento de doenças está associado aos determinantes fisiológicos que, acrescidos das precárias condições de vida, transformam processos aparentemente naturais (crescimento, gravidez, parto e envelhecimento) em graves problemas sociais. Apresenta-se um breve quadro histórico e sociológico da situação 
subalterna em que vivem há séculos os afro-brasileiros e os seus possíveis efeitos sobre a 'saúde da população negra'. ${ }^{5}$

É importante destacar que o diagnóstico apresentado em 1996 não se traduziu na proposta de uma política focalizada. Concluiuse que não haveria "justificativa técnica para a criação de vários programas governamentais de saúde específicos para a população negra, como pretendiam algumas correntes do setor" (p. 2). Exceção deveria ser feita ao Programa de Anemia Falciforme (PAF) em razão de "ser uma doença incidente predominantemente sobre a população afro-descendente e já contar com sinalizadores estatísticos suficientes e convincentes para justificar sua prioridade como problema de saúde pública". ${ }^{6}$

Na perspectiva da 'política de identidade', o PAF é um bom exemplo dos esforços envidados para racializar uma doença e, conseqüentemente, de produzir a 'raça negra' (Fry, 2004a). Esta visão não se limita a uma construção social, fruto das assimetrias e das iniqüidades criadas pelo racismo, mas é naturalizada mediante evidências oriundas da genética. É relevante ressaltar a variada geografia da anemia falciforme, originária na África, mas que se disseminou pela região mediterrânea, Península Arábica, Índia e países do continente americano. De acordo com Zago (2004, p. 370): “embora predomine ainda entre os afro-descendentes, a miscigenação crescente vai fazendo dela uma doença sem vínculo claro com a etnia". Ela foi objeto de controvérsia nos Estados Unidos em função da política adotada pelo governo de focalizar suas ações apenas nos afro-americanos, gerando receios entre lideranças negras de uma potencial estigmatização dessa população (Tapper, 1999, p. 118-21).

Não obstante afirmar ser prescindível uma política compensatória voltada para a 'saúde da população negra', a proposta de 1996 era ambivalente ao procurar simultaneamente colocar em evidência as especificidades do recorte racial enquanto campo de reflexão e de intervenção a ser reconhecido pelo Estado. Em 1997, é definida a "Política de Saúde para a População Negra", na gestão do Ministro Carlos Albuquerque (Oliveira, 2002, p. 243), um passo a mais no caminho do estabelecimento de uma política focal. Na esteira dessa decisão reitera-se o programa estabelecido no ano anterior.

Uma das primeiras demandas atendidas pelo governo FHC foi a inclusão, ainda no início de 1996, do "quesito raça/cor ... nos formulários oficiais, nacionalmente padronizados, de Declaração de Nascidos Vivos e de Declaração de Óbitos" (p. 5). ${ }^{7}$ Além disso, a partir da reunião ocorrida em abril de 1996, o PAF tornou-se, nas palavras de Oliveira (2002, p. 238), "a conquista política mais importante do Movimento Negro na área da saúde". Até março de 2001, enquanto política federal, o PAF, segundo Roland (2001b, p.1): "não saiu do papel". Ele ficou restrito a algumas iniciativas no âmbito municipal e estadual, não se constituindo em um con- 
junto de diretrizes nem tampouco resultando na alocação de recursos por parte do Ministério da Saúde. Acrescente-se o fato de que em junho de 2001 o Ministro da Saúde, José Serra, instituiu, no âmbito do SUS, o Programa Nacional de Triagem Neonatal (PNTN), buscando a cobertura de $100 \%$ dos recém-nascidos vivos e incluindo doenças falciformes e outras hemoglobinopatias. $\mathrm{O}$ PNTN foi visto, por representantes do movimento negro, como uma medida de alcance limitado, quando comparado com a proposta do PAF, e uma forma de diluir uma 'conquista política '(Oliveira, 2002, p. 239-41).

Até o início do segundo semestre de 2001, o governo FHC manifestou uma atitude oscilante em matéria de 'políticas raciais'. Em princípio, ele não julgou pertinente implantar programas específicos de saúde para a população negra, a exceção do PAF. Todavia, este se revelou uma declaração de intenções, um 'bem simbólico', sendo substituído pelo PNTN. A Conferência de Durban promoverá alterações pontuais, porém decisivas a médio prazo, como veremos a seguir.

\section{Sob o efeito de Durban}

Diversas conferências regionais e mundiais serviram de catalisadores para a inserção da discussão sobre o racismo na pauta de questões nacionais e, especificamente, a proposta de construção da 'saúde da população negra'. A 3a Conferência Mundial de Combate ao Racismo, Discriminação Racial, Xenofobia e Intolerância Correlata, realizada em Durban, África do Sul, entre 31 de agosto e 8 de setembro de 2001, foi um momento de inflexão do debate sobre a discriminação racial no Brasil e, em particular, da atuação no período final do governo Fernando Henrique Cardoso (Maggie \& Fry, 2004).

Os fóruns preparatórios para a Conferência de Durban deixaram mais evidentes as articulações entre o movimento negro, no plano transnacional, e a rede de movimentos, ONGs, organizações multilaterais e aparatos estatais no âmbito da luta pelos direitos humanos. Se nos anos 80 a luta anti-racista era representada pela aliança entre cientistas sociais e o movimento negro, com reduzido raio de influência, a partir da segunda metade dos anos 90 e, em particular, no início do século XXI, novos atores se posicionaram a favor da implementação de 'políticas raciais'. Agências do Estado como o Ipea e o Itamaraty, jornalistas, economistas, setores da academia e parlamentares de variados matizes ideológicos passaram a se identificar com a pauta de reivindicações discutida em arenas internacionais, em que políticas públicas racializadas deveriam ser o norte para se atingir justiça social, em contraposição às de perfil universalista (Htun, 2004; Grin, 2004b). 
As ativistas negras brasileiras tiveram papel decisivo na articulação entre demandas formuladas em fóruns globais e as reivindicações locais. $\mathrm{O}$ acúmulo da experiência da luta feminista no campo da saúde reprodutiva e em conferências apoiadas por agências multilaterais (Beijing, Cairo), desde os anos 90, foi decisivo para a busca de legitimação da 'saúde da população negra'. Uma série de eventos preparatórios ocorridos no Brasil e na América Latina para a conferência de Durban combinou a denúncia do racismo e das desigualdades raciais e propostas de políticas de ação afirmativa que, no caso brasileiro, vêm sendo traduzidas pela implantação do sistema de cotas raciais. Um indicador preciso da importância da presença brasileira em Durban foi a escolha de Edna Roland, da ONG Fala Preta!, como relatora (Carneiro, 2002; Barrios, 2002; Oliveira \& Sant'anna, 2002). ${ }^{8}$

Apesar das controvérsias entre Estados Unidos, Israel e países árabes em torno da questão palestina ou das contendas entre países europeus e africanos acerca do legado da escravidão e da reivindicação de reparação, os resultados da Conferência para a rede próação afirmativa no Brasil foram positivos, principalmente quanto à recepção das propostas no país. Em consequência, o governo brasileiro, signatário da Declaração Final de Durban e interessado em manter uma boa imagem no exterior no plano dos direitos humanos, adotou em alguns ministérios cotas raciais para a contratação de pessoal (Desenvolvimento Agrícola e Reforma Agrária, Justiça e Relações Exteriores). Essa mesma política deslanchou em universidades públicas (estaduais e federais) e vem se expandindo desde o final de 2001 (Telles, 2003).

No campo da saúde pública, foi realizada, sob o efeito de Durban, em dezembro de 2001, uma reunião que resultou no documento Política Nacional de Saúde da População Negra (Pnud \& Opas, 2001). Produzido por profissionais de diversas organizações internacionais, do movimento negro e de representantes de instituições universitárias, ${ }^{9}$ o documento informa que a participação brasileira na Conferência Mundial Contra o Racismo produziu um "ambiente favorável" para uma atuação "mais incisiva na superação das desvantagens sociais geradas pelo racismo" (Pnud \& Opas, 2001, p. 5).

Ressalta-se que a inclusão da temática racial nas ações de promoção da equidade em saúde foi impulsionada pelo Plano de Ação da Conferência Regional das Américas Contra o Racismo, realizada no final de 2000 (Santiago, Chile), no qual há uma requisição para que a Organização Pan-Americana de Saúde (Opas) "promova ações para o reconhecimento de raça/grupo étnico/gênero como variável significante em matéria de saúde e que desenvolva projetos específicos para prevenção, diagnóstico e tratamento de pessoas de descendência africana" (Pnud \& Opas, 2001, p. 5). ${ }^{10}$ A formulação de políticas públicas centradas na 'saúde da população negra' é 
justificada pelas evidências de que a "discriminação racial leva a situações mais perversas de vida e de morte", pela utilização dos dados do Ipea, com base no modelo bipolar, sobre as desigualdades entre negros e brancos quanto à escolaridade, à renda e ao saneamento e pelo fato de a universalidade dos serviços, garantida pelo Sistema Único de Saúde (SUS), não ser suficiente para "assegurar a equidade ... ao subestimar as necessidades de grupos populacionais específicos", colaborando para o agravo "das condições sanitárias de afro-brasileiros" (Pnud \& Opas, 2001, p. 6-7). Os limites do SUS, ao supostamente não capturar o 'resíduo' persistente do racismo, exigiriam a elaboração de uma política focal em matéria racial.

A publicação reafirma o conjunto de agravos julgados mais freqüentes na população negra no Brasil. São feitas as seguintes recomendações: produção de conhecimento científico, capacitação dos profissionais da saúde, divulgação de informações à população e formulação de políticas focais de atenção à saúde. O documento traz também a demanda por reconhecimento oficial da medicina popular de 'matriz africana' (Pnud \& Opas, 2001, p. 11). A longa tradição de interação cultural desenvolvida durante séculos entre portugueses, africanos e indígenas e que gerou um rico e diversificado conhecimento médico e de terapêuticas no Brasil, a denominada 'medicina popular', finda por ser reduzida ao legado da população negra. Essencializam-se, nesse caso, os saberes populares amalgamados em nome da afirmação de uma 'cultura negra autêntica'.

Durante boa parte da gestão FHC prevaleceu uma posição ambivalente quanto aos meios de se combater o racismo. O governo a um só tempo estimulou a formulação de políticas especificas para a população negra e demonstrou reservas quanto à adoção de um modelo racializado à norte-americana (Grin, 2001; 2004a). Nesse sentido, abriu espaço para a discussão de políticas de ação afirmativa, pressionado por movimentos sociais e agências internacionais, especialmente após Durban, mas a implementação das mesmas foi tímida, inclusive no campo da saúde pública.

\section{O governo Lula: implementando política compensatória}

Se no governo FHC as medidas relativas às 'políticas raciais' foram limitadas, por vezes ambivalentes, a eleição de Lula amplia a perspectiva de adoção de políticas focais. Os efeitos de Durban, somados às vinculações do Partido dos Trabalhadores com movimentos sociais, resultaram na criação da Secretaria Especial de Promoção de Políticas de Igualdade Racial no primeiro semestre de 2003 (Seppir). Paralelamente, as interfaces entre aspectos étnico-raciais e saúde ganham crescente visibilidade no debate sobre as desigualdades sociais no Brasil. Para ficar apenas num exemplo, devem-se 
destacar as publicações e informes da Rede Feminista de Saúde e Direitos Reprodutivos, ${ }^{11}$ constituída pela articulação do movimento de mulheres do Brasil, que permite múltiplas evidências da presença do tema nas notícias da imprensa (jornais de circulação nacional); em eventos (seminários, palestras, audiências públicas) promovidos por organizações da sociedade civil, instituições acadêmicas e por agências estatais nas áreas do ensino, saúde e cultura; em publicações diversas (livros, boletins e revistas de divulgação científica), assim como em concursos de teses, prêmios e linhas de financiamento para projetos.

Em agosto de 2004 foi constituído o Comitê Técnico de Saúde da População Negra, integrado por representantes de diversos órgãos e instituições do Ministério da Saúde e da Seppir. O Comitê tem as seguintes atribuições:

I - sistematizar propostas que visem à promoção da equidade racial na atenção à saúde; II - apresentar subsídios técnicos e políticos voltados para a atenção à saúde da população negra no processo de elaboração, implementação e acompanhamento do Plano Nacional de Saúde; III - elaborar e pactuar propostas de intervenção conjunta nas diversas instâncias e órgãos do Sistema Único de Saúde; IV - participar de iniciativas intersetoriais relacionadas com a saúde da população negra; e V - colaborar no acompanhamento e avaliação das ações programáticas e das políticas emanadas pelo Ministério da Saúde no que se refere à promoção da igualdade racial, segundo as estratégias propostas pelo Conselho Nacional de Promoção da Igualdade Racial (CNPIR). (Diário Oficial da União, seção 2, 16.8.2004, p. 19)

Nessa ocasião ocorreu o $1^{\mathrm{o}}$ Seminário Nacional da Saúde da População Negra, entre os dias 18 e 20 de agosto de 2004, em Brasília, patrocinado pelo Ministério da Saúde e pela Seppir. O evento trouxe novos desdobramentos das concepções e propostas apresentadas no documento, previamente mencionado, Política Nacional de Saúde da População Negra: uma questão de eqüidade (Pnud \& Opas, 2001). Entre os presentes encontravam-se gestores em saúde pública, médicos, enfermeiros, representantes de ONGs vinculadas a projetos sociais e ativistas do movimento negro, parte dos quais inseridos em instituições acadêmicas. Os pressupostos e as diretrizes centrados na formulação de uma política de ação afirmativa na esfera da saúde pública voltada para a população negra, além de terem sido reafirmados, foram expandidos. Assim, ao longo do seminário, os trabalhos e discussões reiteraram a importância da implantação do quesito raça/cor nos formulários oficiais de Declaração de Nascidos Vivos e de Declaração de Óbitos e a necessidade de se desenvolver políticas que atendam as especificidades de saúde dos grupos étnico-raciais, ilustrados pelos Programas de Anemia 
Falciforme e Triagem Neonatal, pelas ações em saúde junto às comunidades quilombolas e pelo reconhecimento do saber dos terreiros de candomblé pelo Ministério da Saúde, entre outros. ${ }^{12}$

Para subsidiar as discussões do 1º Seminário Nacional de Saúde da População Negra, a coordenação do evento divulgou um Caderno de textos básicos. Nele, há uma revisão da bibliografia, contextualizando historicamente conceitos considerados importantes para a abordagem do tema 'saúde da população negra', como: cidadania, raça e medicina; racismo; preconceito; democracia racial; racismo institucional; ações afirmativas e empoderamento. São também tratados os princípios do SUS e a controversa relação entre classe e raça/cor. As interações entre movimentos sociais e organizações governamentais relativas aos direitos da população negra e a presença do Brasil em conferências internacionais finalizam o trabalho (Figueroa, 2004).

Nessas análises, valoriza-se o conceito de raça, a despeito das críticas de geneticistas e antropólogos citadas no texto, pelo fato de ser uma categoria sócio-política mobilizada pelo ativismo negro contra o racismo, ou seja, "de marcador pejorativo de traço físico e de uma história de opressão e discriminação, a nova sonoridade do termo raça negra propõe uma racialização positiva na busca da superação definitiva das mazelas enfrentadas pela população negra" (Figueroa, 2004, p. 2).

Presume-se que a proclamada racialização de novo tipo reconhece que 'raça' é uma categoria criada por teóricos do século XVIII, veiculada pelo determinismo biológico do século XIX em nome da divisão hierárquica da humanidade. Julga-se, ao mesmo tempo, que as categorias produzidas pelo racismo científico seriam transformadas em instrumentos privilegiados da luta anti-racista. Guimarães sugere "a necessidade de teorizar as 'raças' como elas são, ou seja, construtos sociais, formas de identidade baseadas numa idéia biológica errônea, mas socialmente eficaz para construir, manter e reproduzir diferenças e privilégios" (1999, p. 64). Caberia então desnaturalizar raça enquanto conceito biológico e enfatizar seu caráter sociológico, como instrumento identitário a ser politizado em nome de uma sociedade mais justa e igualitária.

Para isso, a construção de uma 'política racial' exigiria a eliminação da categoria censitária e intermediária 'pardo' e a sua associação com a categoria 'preto' em função das alegadas similitudes entre os dois grupos na esfera socioeconômica. Assim, pardos e pretos são englobados em não-brancos, em 'raça negra', em 'afrodescendentes', reforçando o padrão bipolar, afeito à experiência norte-americana. ${ }^{13}$ A construção do modelo dicotômico (branco/ negro), por sua vez, facilitaria, na visão de seus proponentes, a tomada de consciência racial que levaria ao reconhecimento identitário. A partir da política de identidades, o Estado viria a aten- 
der as demandas diferenciadas em termos de incorporação social com o fito de se chegar à 'equidade racial'.

Para caracterizar as disparidades raciais são realizados "exercícios estatísticos" (Figueroa, 2004, p. 10), buscando demonstrar ainda as implicações da discriminação racial e, com isso, criticar as perspectivas que subsumem as assimetrias raciais às condições socioeconômicas. Os estudos do Ipea, do IBGE e da parceria Ministério da Saúde-Seppir, com o apoio de agências multilaterais (Pnud, Unesco, Dfid, Banco Mundial), vêm produzindo os dados quantitativos necessários para transformar as diferenças entre brancos e negros em chave explicativa privilegiada para se entender as desigualdades sociais existentes no Brasil.

A consolidação do projeto político de racialização da saúde pública necessita também do incremento da geração de dados estatísticos que evidenciem as clivagens entre brancos e negros na área da saúde. Lembrando Pinto e Souza (2002, p. 1144): "nesse contexto de discussão, novos atores apresentam-se na cena social para apontar a necessidade de dados sobre a situação de saúde da população negra. A produção de informação passou então a ser um forte componente para a construção e fortalecimento da identidade negra".

Os achados estatísticos, conforme indica Pinto (2005, p. 2-3), "costumam ser apresentados como mera expressão da 'realidade' social, deixando-se de lado toda a reflexão epistemológica sobre o impacto dos instrumentos de 'mensuração social' na construção de grupos sociais através da reificação de suas categorias definidoras" ${ }^{14}$ É preciso, portanto, combinar levantamentos quantitativos com análises qualitativas sócio-antropológicas para se aferir, de forma consistente, os mecanismos e os respectivos efeitos do racismo, destoando esse propósito da mera afirmação de identidades políticas.

Cabe ainda destacar que no documento do Seminário Nacional da Saúde da População Negra o conceito de equidade, presente nos princípios do SUS, apresenta uma perspectiva multiculturalista, ao enfatizar que a diversidade cultural existente na sociedade brasileira deve levar em consideração as especificidades daqueles considerados diferentes. No capítulo da cidadania, o documento indica, entre outros aspectos, os 'direitos culturais' (Figueroa, 2004, p. 7). Neles "se inclu[iriam] o de identidade étnica, de opção religiosa, de preservação e valorização das línguas e expressões rituais, musicais ... saberes e práticas médicas e de cuidados tradicionais..." (ibidem, p. 7). Em princípio, pareceria plausível conjugar identidades culturais com cidadania universal. Contudo, a proposta é que minorias, que sofreram injustiças históricas, reivindiquem uma espécie de 'cidadania cultural', inspirada no modelo norte-americano, como forma de romper com a idéia de universalidade e igualdade de direitos em nome de políticas compensatórias (cf. Carvalho, 2000, p. 120). 
Mencionam-se ainda, nos textos do Seminário, o Relatório Preliminar da $12^{\underline{a}}$ Conferência Nacional de Saúde, que tem diversas passagens referentes à população negra que deverão ser integradas às instâncias do SUS, bem como comentários sobre as bases que nortearam a formulação do "Plano Nacional de Saúde: um pacto pela Saúde no Brasil".

O processo de construção de uma política focalizada como resposta às desigualdades raciais em saúde vem sendo acompanhado por um conjunto de portarias recentes voltadas para regulação e implementação de ações junto a comunidades quilombolas e aos Programas de Anemia Falciforme e Atenção aos Pacientes Hemoderivados. Há outras ações nesta direção, como o estímulo a projetos e estudos sobre a vulnerabilidade ao HIV/Aids da população negra, em parceria com o Programa Nacional de DST/HIV/Aids e Seppir, e a proposição de cursos de formação e produção de material educativo para diferentes segmentos populacionais (profissionais de saúde, escolares, auditores) acerca da saúde da população negra, entre outras iniciativas.

\section{Interpretações sobre raça e saúde}

Com base na produção acadêmica, sobretudo biomédica, o propósito deste item é dialogar com algumas idéias expostas no documento divulgado no $1^{\text {o }}$ Seminário Nacional da Saúde da População Negra, de autoria de Lopes (2004), acerca das desigualdades raciais em saúde. ${ }^{15}$ Para isso, dividiremos nossa exposição em quatro tópicos: 1) a utilização do conceito de raça; 2) o emprego da taxonomia bipolar (branco/negro) e da categoria afro-descendente; 3) as relações entre racismo e condições de saúde; 4) a associação entre a epidemia do HIV/Aids e a população negra.

Quanto ao primeiro ponto, Lopes (2004) admite a inconsistência da determinação biológica do conceito de raça e destaca o seu caráter histórico e social. Em seguida, informa que raça será concebida "como sinônimo de grupo de pessoas socialmente unificadas em virtude de seus marcadores físicos" (2004, p. 49). Embora reconheça a polissemia do termo, ela não incorpora diversos níveis de problematização presentes na literatura acerca das implicações da utilização da dimensão racial nas pesquisas em saúde. Um deles refere-se à imprecisão freqüentemente observada ao se empregar categorias como raça, etnia e/ou etnicidade na produção acadêmica na área da saúde. As variações conceituais tendem a comprometer a interpretação das diferenças nos indicadores de saúde entre os grupos étnico-raciais (Anand, 1999; Ferreira et al., 2003). ${ }^{16}$

Na pesquisa acerca dos variados significados de raça nos artigos do South African Medical Journal, Ellison e De Wet (1997) afirmam a necessidade de se utilizar com cautela tais definições, visando 
evitar a legitimação do conceito biológico de raça, o que reforçaria o preconceito racial. A partir de um ângulo complementar, McDermott (1998) examina os perigos da associação acrítica entre doença e raça, discutindo a hipótese da base genética (hipótese do Thrifty genotipe) como causa explicativa para a epidemia de diabetes, principalmente nas sociedades indígenas do período pós-colonial. $\mathrm{O}$ autor põe em questão as evidências, sustentadas em dados epidemiológicos, que apóiam a teoria da presença de um fator genético imutável associado a grupos étnicos, ao invés de heranças ou fatores metabolicamente adaptados e, conseqüentemente, mutáveis, que tornam tais grupos mais vulneráveis. Tal perspectiva, segundo McDermott (1998), exclui a análise da influência dos fatores sociais na definição da doença e, conseqüentemente, prejudica a adoção de medidas de assistência e prevenção.

As contribuições recentes no campo da genética na definição de padrões de saúde ilustram as controvérsias em torno do tema. Risch et al. (2002) apresentam evidências que apóiam o uso de cinco categorias de auto-identificação racial, tendo por base a definição clássica de ancestralidade continental das raças, a saber: africanos, caucasianos, nativos do pacifico, asiáticos e americanos nativos. ${ }^{17}$ Segundo autores a identificação das diferenças entre os grupos raciais e étnicos é cientificamente pertinente para o estudo de marcadores genéticos e de genes associados à suscetibilidade a doenças e respostas ao uso de drogas (2002, comment 2007.11). Numa perspectiva crítica, Cooper (2003) afirma que as evidências de que a raça ou 'ancestralidade continental' tenham um significado genético são insuficientes. As variações genéticas associadas às doenças, em geral, não são traços raciais, mas mutações randômicas em subpopulações ou o resultado de seleções regionais particulares associadas a grupos populacionais específicos. A seu ver, até o momento não há provas de que o padrão de doenças crônicas, como a hipertensão, resulte de uma origem genética.

Para Karter (2003), as visões de Cooper (2003) e de Risch et al. (2002) são problemáticas. Diante dos exemplos de diferenças raciais em determinadas doenças (câncer de próstata, glaucoma etc.) e respostas terapêuticas (alta dose de interferon para hepatite crônica) que persistem após o controle de potenciais confundidores ${ }^{18}$ (acesso a atendimento médico, status socioeconômico, comportamento saudável), o autor sugere o uso de análises estratificadas por raça de doenças complexas. A despeito de reconhecer a falta de precisão da auto-identificação racial, afirma ser preciso utilizá-la pelo rendimento analítico que oferece para as pesquisas epidemiológicas e genéticas.

Uma segunda questão a ser destacada no trabalho de Lopes (2004) refere-se à proposição do padrão bipolar branco/negro na análise das disparidades raciais em saúde no Brasil. Ela insere pretos e par- 
dos na categoria negro e, portanto, não atenta para os problemas dessa junção, conforme salientados por Travassos e Williams (2004, p. 675-6) a partir da análise comparada Brasil-EUA. Os autores alegam que tal associação (pardos + pretos = negro) é uma abordagem questionável para medir pessoas com ancestralidade africana no Brasil, dado que a cor não é um marcador genético consistente na população. Ademais, 'pardo' não inclui apenas pessoas com ancestralidade africana, mas também, por exemplo, a mistura de brancos e índios (caboclos). A agregação dos termos 'pretos' e 'pardos' é igualmente criticada em função das variações demográficas e socioeconômicas entre os dois grupos e pelo fato de não respeitar a classificação da cor/raça feita pelos indivíduos. A etnicidade, por sua vez, não aparece como uma alternativa para a classificação da cor/raça, haja vista que a sociedade brasileira não apresenta divisões culturais claras (2004, p. 670).

O esforço de produção de uma sociedade bicolor, com a eliminação de categorias nativas (caboclo, moreno, curiboca etc.) ou oficiais intermediárias, como é o caso do pardo, levou Carvalho (2004) a denominá-lo "genocídio racial estatístico". Este fenômeno pode ter implicações de não pouca monta para o campo da saúde pública, como se pode depreender do estudo de Paixão (2005). ${ }^{19}$ Ele revela que não há convergência entre pretos e pardos em alguns 'indicadores vitais' nacionais. O autor constatou, por exemplo, que entre homens e mulheres pretos as taxas de mortalidade eram superiores a $15 \%$ quando comparadas com homens e mulheres pardos nas seguintes causa e mortis: tuberculose, infecções bacterianas, infecções sexuais, HIV/Aids, neoplasias, doenças endócrinas e nutricionais, diabete mellitus, desnutrição, uso de psicotrópicos, doenças alcoólicas do fígado, doenças do aparelho circulatório, hipertensão, doenças do coração, acidentes cérebro-vasculares, doenças do aparelho respiratório e doenças intestinais (Paixão, 2005, p. 374) ${ }^{20}$ Assim, o uso do modelo identitário dicotomizado (branco/preto), preconizado pelo movimento negro, mostra-se inadequado para classificar nos estudos em saúde pública populações muito miscigenadas como a brasileira (Bastos \& Travassos, 2005, p. 470).

Merece comentário ainda o uso da categoria 'afro-descendente' por Lopes (2004) e, de forma recorrente, em documentos do Ministério da Saúde. ${ }^{21}$ Ao valer-se desse termo para definir possíveis beneficiários de políticas públicas, e para o estabelecimento de correlações com determinadas doenças, não se leva em conta sua própria imprecisão conceitual. Indo além, cabe continuar utilizando uma categoria, marcadamente política (negros/afro-descendentes = pretos + pardos), quando estudos genômicos destacam que $86 \%$ da população brasileira apresenta mais de $10 \%$ de ancestralidade africana e que $48 \%$ dos afro-descendentes se classificam como 'brancos'? (Pena \& Bortolini, 2004). Pelo que se pode observar, a biologia 
contemporânea não apenas questiona a validade do conceito de raça, mas parece também interpelar a reificação da identidade afrodescendente ao revelar um país de reconhecida mistura gênica.

Um terceiro aspecto tratado por Lopes (2004) está associado à manutenção das piores condições de existência (renda, educação, habitação) dos negros quando comparados aos brancos, assim como às implicações negativas da discriminação racial para a inserção no mercado de trabalho, mobilidade social e autoconfiança dos negros, com repercussões na saúde física e psicológica. Os danos da discriminação étnico-racial na produção das desigualdades em saúde também são alvo de discussão. Para Geronimus (2000) os segmentos étnicos minoritários têm sofrido maior dificuldade de ascensão social, quando comparados à população branca, em função da falta de acesso à educação, à saúde, ao emprego e à habitação de qualidade. Essas limitações se integram aos efeitos do preconceito étnicoracial, mais ou menos explícitos, nas experiências do cotidiano, gerando estresse psicológico e baixa auto-estima e fomentando o quadro de falta de equidade social, com reflexos na saúde.

É preciso, todavia, levar em conta os desafios de ordem teóricometodológica na compreensão do fenômeno. Com base em estudos no Reino Unido e nos Estados Unidos, Nazroo (2003) afirma que as análises das condições socioeconômicas na compreensão das desigualdades étnico-raciais em saúde são contestáveis. Segundo o autor, os dados não contêm informações detalhadas sobre a etnicidade dos respondentes, capazes de identificar a heterogeneidade entre os grupos; os indicadores sobre as condições de vida são incompletos, pois não incluem, por exemplo, outras dimensões da desigualdade social como experiências de discriminação. Na sua visão é indispensável reconhecer a relevância dos estudos dos contextos nacionais e dos processos de formação dos grupos étnicos e investigar de que modo tais particularidades se relacionam com as desigualdades socioeconômicas, e como elas influenciam as desvantagens experimentadas pelas minorias étnicas (2003, p. 283).

Demais estudos sobre o racismo na saúde ilustram a necessidade de se investigar, de forma mais pormenorizada, determinadas dimensões desse fenômeno. Wyatt et al. (2003) examinam as relações de doenças cardiovasculares entre os negros e os níveis de discriminação étnico-racial decorrentes: do 'racismo institucional', que pode limitar as oportunidades de mobilidade social e, conseqüentemente o acesso a bens e recursos materiais; do 'racismo percebido', capaz de promover situações estressantes e, com isso, induzir reações psicofisiológicas prejudiciais à saúde; do 'racismo internalizado', que pode gerar uma auto-avaliação negativa em função da assimilação de estereótipos negativos. Para os autores, há indicações sobre a importância das redes sociais de apoio (por exemplo: familiar, religiosa, comunitária) na amenização das respos- 
tas gerais ao estresse. Estudos qualitativos das práticas cotidianas poderiam iluminar as razões das diferenças nas respostas ao racismo. A validação de modelos conceituais, acerca dos fatores fisiológicos, comportamentais e sociais que regem essas diferenças, requer a realização de investigações longitudinais, capazes de verificar tais fatores, incluindo os vários níveis de racismo e as outras formas de opressão relativas ao gênero, idade e/ou classe social.

Os trabalhos sobre as implicações da discriminação racial no acesso e na qualidade dos serviços de saúde também têm sido alvo de investigações. Pondera-se que o tratamento diferenciado entre os grupos étnico-raciais na área da assistência é um dos responsáveis pelas desigualdades raciais em saúde. Nesse eixo de análise, vêm sendo realizadas investigações na área do planejamento, gestão e avaliação de serviços (Fiscella et al., 2000; Cooper et al., 2002; Ryn \& Fu, 2003).

As diversas reflexões apresentadas sobre as desigualdades étnicoraciais em saúde têm por objetivo nuançar certos pressupostos que vem orientando políticas particularistas. Krieger (2003) reconhece que as conseqüências do racismo para a saúde da população são conhecidas, mas pouco investigadas. Para tal, faz-se necessário definir, de forma clara, os conceitos de racismo e raça/etnia. Não confundir as 'expressões biológicas das relações raciais' (que analisam de que modo os danos da exposição física e psicológica decorrentes do racismo afetam de forma adversa a nossa constituição biológica) com a 'racialização das expressões biológicas' (que se refere a como traços biológicos arbitrários são erroneamente construídos como marcadores inatos de diferenças raciais). É preciso ainda considerar as abordagens diretas do racismo, relativas às percepções dos indivíduos, como as indiretas, que estão além da percepção individual, por meio de métodos qualitativos e quantitativos. Krieger também sugere estudos mais aprofundados sobre as relações entre raça e saúde que contribuam para o entendimento das desigualdades em saúde.

Depreende-se que os procedimentos metodológicos capazes de captar as conseqüências da experiência do racismo para a saúde devem ser formulados a partir das contribuições dos diversos campos disciplinares, em particular das ciências sociais e da saúde (Harell et al., 2003). A revisão de Williams et al. (2003) sobre as evidências das associações entre a percepção da discriminação étnico-racial e saúde em estudos de base populacional, publicados entre 1998 e 2003, convergem com a necessidade de se avançar nas investigações nesse campo. Eles constataram a falta de consenso na literatura sobre a melhor forma de medir a exposição ao racismo, a importância da diferenciação entre as experiências recentes e cumulativas, e as contribuições dos estudos sobre estresse para se investigar a discriminação, entre outros aspectos. Frente a tais evidências, os autores concluíram que as relações entre discriminação e agravos à 
saúde tendem a ser associadas a fatores diversos afetando, sobretudo, grupos socialmente desfavorecidos. Todavia, os estudos realizados nesse campo apresentam limitações na compreensão desse fenômeno (2003, p. 206).

Um quarto e último ponto do trabalho de Lopes (2004) refere-se às "condições especiais de vulnerabilidade" aos agravos à saúde, entre os quais a epidemia de HIV/Aids, da população negra no Brasil, em decorrência das condições sociais adversas. Tendo em vista que nos últimos anos a epidemia de Aids tem atingido as populações mais pobres, parece ser precipitado vincular a raça negra ao aumento da vulnerabilidade a Aids. O caso do programa Afroatitude, patrocinado pelo Programa Nacional de DST/Aids, em parceria com a Seppir, estimula a pesquisa sobre as relações entre Aids e raça negra e sugere que alunos que ingressaram nas universidades por meio do sistema de cotas raciais pesquisem os laços entre a epidemia e "questões sociais, econômicas e culturais dos afro-descendentes". ${ }^{22}$ Conforme assinala Fry (2004b), tais associações fomentam o surgimento de outro grupo de risco. A atribuição de componentes culturais à vulnerabilidade ao HIV de negros pobres, diferenciada de brancos pobres, contribui para a naturalização da raça e da cultura negras.

Embora os argumentos assinalados não esgotem a riqueza e amplitude das questões envolvidas na compreensão das desigualdades étnico-raciais em saúde, tais reflexões têm o propósito de fomentar o debate sobre a pertinência da formulação e implementação de políticas voltadas para a 'saúde da população negra' no Brasil. A utilização dos conceitos de raça e/ou etnia na abordagem das doenças 'geneticamente determinadas', ou os instrumentos teóricometodológicos para se aferir a influência do racismo nos agravos à saúde, ainda são objeto de intenso debate na produção acadêmica, especialmente a anglo-saxã. Essa literatura vem sendo apropriada seletivamente em função do projeto de racialização da saúde pública em curso no Brasil.

\section{Considerações finais}

A formação do campo da 'saúde da população negra' ocorre no momento em que o debate sobre o racismo e a formulação de programas de ação afirmativa assumem crescente visibilidade na cena brasileira. Trata-se da construção de uma política setorial, com recorte racial, gerador de um processo de diferenciação e de busca de legitimação - no âmbito da saúde pública - dos agravos sofridos pelos negros. A criação dessa distinção requer a produção de especificidades, de características próprias à 'raça negra'. Esse processo em curso tem seu ponto de partida no mandato inicial de Fernando Henrique Cardoso, quando se operou uma primeira inflexão 
Nossos

agradecimentos a José Augusto Drummond pela leitura cuidadosa que fez de versão preliminar do texto. Somos também gratos aos dois pareceristas anônimos de História, Ciências, Saúde Manguinhos pelas críticas e sugestões. na história do racismo no Brasil com o reconhecimento oficial de sua existência no país. Nesse contexto, houve o encontro entre demandas do ativismo negro e um presidente da República sensível à questão racial, resultando no surgimento do Grupo de Trabalho Interministerial Para a Valorização e Promoção da População Negra.

A proposta de uma política focal da 'saúde da população negra' só adquire proeminência após a Conferência de Durban, no segundo semestre de 2001. Ela ajudou a formar uma agenda antiracista racializada por movimentos sociais, setores da academia e da mídia, agências estatais e multilaterais, e fundações filantrópicas norte-americanas. Ela é um indicador preciso de como pautas nacionais são definidas em arenas internacionais. O 'efeito Durban' logo se fez presente, seja na adoção de cotas raciais no ensino superior, seja na implementação de políticas raciais no âmbito do trabalho, da saúde e do setor agrário, sob a égide dos Direitos Humanos e da justiça social.

Esse fórum internacional teve reflexos mais visíveis no governo Lula, com a ampliação do debate e da implantação de políticas compensatórias, e a criação da Secretaria Especial de Promoção de Políticas de Igualdade Racial (Seppir), com status de ministério. Essa agência estatal vem estabelecendo uma série de parcerias com outros ministérios, com impactos diversos no campo da saúde pública.

Esses eventos ocorrem simultaneamente à redução da participação do setor público na área social, em face dos ditames da política macroeconômica. Diante do Estado com funções reduzidas, como proclamado pelo neoliberalismo, a focalização transformou-se em pedra de toque dos supostos limites das políticas universalistas. Talvez, como efeito não antecipado, as políticas centradas em 'raça' se ajustem às exigências da era global. ${ }^{23}$

Tal perspectiva se distancia da tradição sanitarista brasileira, construída sob o signo do universalismo, chancelada pelo Estado. O movimento da Reforma Sanitária, calcado no tripé universalidade, integralidade e gratuidade, conforme inscrito na Constituição Federal, concebe a saúde como um direito universal de cidadania. Com todos os percalços existentes no campo da saúde pública no país, existe um consenso de que a reforma da saúde é um dos mais bem-sucedidos projetos políticos de incorporação dos setores populares, segmentos esses com expressiva presença de negros.

Existem diversos desafios à 'racialização positiva' preconizada pelo movimento negro no domínio da saúde pública. Diferentemente dos arautos da naturalização das hierarquias raciais do século XIX, os partidários do racialismo de novo tipo, em pleno século XXI, concebem que as categorias produzidas pelos opressores, como o conceito de raça, podem informar utopias libertadoras. Há que pensar sobre as conseqüências desse processo, como alerta Gilroy (2000). A análise da construção de uma política racializada 
no campo da saúde pública, acrescida dos questionamentos presentes na produção acadêmica principalmente biomédica, focos do presente artigo, tiveram o propósito de contribuir para um importante e necessário debate entre os diversos atores envolvidos no enfrentamento das desigualdades sociais e na atualização da discussão sobre as formas de combate ao racismo no Brasil.

\section{NOTAS}

${ }^{1}$ Utilizaremos a expressão 'saúde da população negra' sempre entre aspas simples, por constituir um termo criado pelos atores envolvidos na formação do próprio campo de reflexão e de intervenção social que a expressão vem designar. Procuramos estar atentos a possíveis processos de naturalização, de reificação de uma categoria que é política e denota a busca da produção de singularidades nas relações saúde/doença associadas a determinado grupo demográfico.

2 Poderíamos inferir, inspirando-nos em Grin (2004b), que o movimento da Reforma Sanitária, uma espécie de intelligentsia, estaria informado por alguns princípios da tradição de esquerda, de corte nacionalista, que veria com estranheza um mundo movido através de constructos raciais, a saber: "1) longa tradição sociológica que opera com a categoria de classe social para tratar as desigualdades sociais; 2) tradições de esquerda cuja utopia socialista e nacionalista não concebe atores raciais; 3) sensibilidade moral cujo princípio de justiça identifica na privação absoluta o foco para o qual a sociedade deve estar mobilizada..." (p. 100).

${ }^{3}$ Há uma racialização de novo tipo em curso no Brasil. A recente corrente racialista não apenas concebe a existência, em princípio, de raças como constructos sociais, mas acredita que só a partir do desvelamento de uma 'ordem racial' assimétrica, mediante a racialização das relações sociais, se atinge igualdade substantiva.

4 Ver: Barbosa, 1998; Oliveira, 1999; Olinto \& Olinto, 2000; Jornal da RedeSaúde, 2001.

${ }^{5}$ O programa da mesa 'Saúde da População Negra' foi extraído de www.planalto.gov.br/pwubli_04/colecao/ racial.2h.htm, acesso em 23.1.2004.

${ }^{6}$ Quanto aos dados sobre a anemia falciforme, o documento revela informações ainda muito imprecisas: “Os técnicos que têm trabalhado com essa doença estimam a existência de dois a dez milhões de portadores do traço falciforme e 8 a 50 mil doentes, segundo cálculos elaborados com base em probabilidades estatísticas. O PAF trabalha com patamares inferiores dessas estimativas. Em números reais, o cadastro nacional tem o registro de 4 mil doentes, ficando a diferença por conta da não-notificação ao órgão central dos casos diagnosticados como outras doenças ou sem diagnóstico por falta de acesso aos serviços de saúde".

7 Foram também implementadas as seguintes propostas: 1) financiamento de pesquisas clínicas sobre anemia falciforme e projeto de saneamento em comunidades de remanescentes de quilombos; 2) publicação de estudos sobre anemia falciforme (Jaccoud \& Beghin, 2002, p. 59).

${ }^{8}$ No contexto dos preparativos para a Conferência de Durban, por ocasião da Pré-Conferência Cultura \& Saúde da População Negra em Brasília (13 a 15.9.2000), foi lançado pela Secretaria de Políticas de Saúde do Ministério da Saúde o Manual de doenças mais importantes, por razões étnicas, na população brasileira afro-descendente. Disponível em: www.redesaude.org.br/jornal/html/body_jr22-enc-abertura.html, acesso em 23.3.2005.

9 Participaram da elaboração do documento: um sanitarista, um consultor legislativo, sete membros de organizações internacionais (Unicef, Unesco, Pnud, Opas, UNDCP, GT-Unaids), um da Secretaria de Saúde do Estado do Rio de Janeiro, cinco profissionais de organizações do movimento social (AMMA, CRIOLA, RedeSaúde, Fala Preta, Associação Anemia Falciforme) e três de Universidades Federais (UFBA, UFF, UFMT).

${ }^{10}$ Um exemplo da participação mais efetiva de organizações internacionais neste campo após a Conferência de Durban foi a publicação pela Opas do livro Saúde da população negra: Brasil, da médica, líder feminista e ativista negra Fátima de Oliveira. Ver Oliveira (2002).

${ }^{11}$ Fundada em 1991, a RedeSaúde reúne 182 grupos feministas e pesquisadoras que desenvolvem trabalhos políticos e de pesquisa nas áreas da saúde da mulher e dos direitos reprodutivos. Para este artigo, foram consultados os boletins eletrônicos Saúde Reprodutiva na Imprensa, os informativos eletrônicos da RedeSaúde e os jornais da Rede Feminista de Saúde, divulgados no período de janeiro de 2001 a julho de 2003, assim como os demais conteúdos da página da Rede Saúde referentes aos dossiês, artigos e dados, campanhas, folhetos e cartilhas (www.redesaude.org.br). 
12 Esta parte do nosso artigo tem por base os seguintes documentos: Ministério da Saúde - Políticas, Programas e Ações: alguns exemplos (Seppir; MS, 2004a), Cadernos de Textos Básicos (Seppir; MS, 2004) e Relatório do Comitê Técnico de Saúde da População Negra (MS, 2004); Macedo (2004).

13 Figueroa não deixa margem a dúvidas sobre o processo de 'racialização positiva' de pardos e pretos em negros quando aborda as populações indígenas da região Norte. A seu ver: "é provável que sob a categoria 'pardo', proposta no cardápio fechado do IBGE, tenham entrado aqueles que, na nomenclatura regional da Amazônia, se denominam 'caboclos'. Essa categoria, que engloba a grande maioria da população do Norte, embora denote mestiçagens diversas, assinala para uma ascendência predominantemente indígena. $\mathrm{O}$ seu enquadramento como negro, no entanto, é plausível como sinalização de sua condição historicamente subordinada na relação ao branco. Como assinalou uma pesquisadora liderança negra [sic], no marco das relações interétnicas vigentes, índios e caboclos estão sujeitos ao mesmo tratamento que é dado aos negros" (2004, p. 4-5).

14 Batista e Kalckmann (2005, p. 21) elucidam bem essa questão ao afirmarem: “os gestores do sistema, e também a Academia, diziam: 'Provem isso, vocês não têm números para mostrar o que estão dizendo. Se adoecer tem a ver com condições de vida, então os negros morrem mais porque são pobres'. Para estes atores o Brasil vive uma democracia racial, o racismo não existe e/ou tem pouca importância nas relações sociais. Essa argumentação justifica e mantém invisível o tema saúde da população negra" (grifo no original).

15 A literatura internacional, especialmente a norte americana, sobre as interfaces entre raça e saúde é expressiva, mas a produção nacional ainda é incipiente. Esse cenário vem mudando em função do interesse que o tema vem adquirindo entre pesquisadores do campo da saúde coletiva (Monteiro, 2004; Monteiro \& Maio, 2005). Pesquisadores presentes no IV Congresso Brasileiro de Epidemiologia, em junho de 2004, chamaram a atenção para a presença pouco comum de estudos com recorte racial no evento. Outro indicador deste novo cenário são as seguintes publicações: Boletim do Instituto de Saúde (2003); Travassos \& Williams (2004); Almeida-Filho et al. (2004); Batista et al. (2004); Chor et al. (2004); Maio et al. (2005); Laguardia (2004); Leal et al. (2005).

16 Kaplan e Bennet (2003) defendem a pertinência de os periódicos científicos estabelecerem padrões para fundamentar o uso dos termos 'raça' e 'etnicidade' nas investigações em saúde.

17 Tendo por base pesquisas genéticas populacionais, os autores propõem a seguinte categorização: 'Africanos': aqueles com ancestralidade na África Sub-saariana, os Afro-Americanos e Afro-Caribeanos; 'Caucasianos': aqueles com ancestralidade na Europa e na Ásia Ocidental, incluindo a subcontinente indiano, o Oriente Médio e os Africanos do Norte; 'Asiáticos': os da Ásia Oriental (China, Indochina, Japão, Filipinas e Sibéria). Os 'Nativos do pacifico' referem-se aos originários da Austrália, Papua Nova Guiné, Melanésia e Micronésia, e os 'Americanos nativos' são aqueles originários das Américas do Sul e do Norte. Há grupos na fronteira desta divisão continental que se mostram de mais difícil classificação, o que não invalida a existência da estrutura genética de base racial na população humana (2002, 2007.4).

18 Confundidores são considerados vieses capazes de comprometer a análise.

${ }^{19}$ Microdados da amostra do Censo Demográfico de 1980, 1991 e 2000; microdados do suplemento da pesquisa nacional por Amostra de Domicílios (PNAD), 1988 e 1998; microdados do Sistema de Informação de Mortalidade/Datasus, triênio 2000-2002 (Paixão, 2005, p. 361).

${ }^{20}$ Paixão (2005) ressalta em seu trabalho o problema das subnotificações como uma questão a ser levada em consideração sobre a qualidade dos dados de mortalidade contidos no Datasus.

${ }^{21}$ No "Plano Nacional de Saúde/PNS - Um Pacto pela Saúde no Brasil", aprovado pelo Ministério da Saúde mediante a portaria n⿳0 2.607, de 10.12.2004 (Diário Oficial da União, n. 238, 13.12.2004), aparece inúmeras vezes o termo afro-descendente. Sobre a participação de geneticistas no debate acerca de políticas públicas racializadas, ver Maio \& Santos (2005).

22 O Programa Nacional DST/Aids lançou em dezembro de 2004, em conjunto com a Secretaria Especial dos Direitos Humanos (SEDH) e a Secretaria Especial de Promoção da Igualdade Racial da Presidência da República (Seppir), e com a Secretaria de Ensino Superior do Ministério da Educação (SESU), o Programa Brasil Afro Atitude - um programa de bolsas para alunos negros cotistas de cursos de graduação de universidades públicas, que condiciona o envolvimento desses alunos com o tema 'Aids e racismo'. Convergente com esta perspectiva, o Programa Nacional de Aids lançou edital de chamada para seleção de pesquisas em DST/HIV/Aids que visam aprimorar o conhecimento científico e tecnológico no que se refere à relação entre condições de vulnerabilidade à infecção pelo HIV e ao adoecimento por Aids na população negra (convocatória n. 2/2005, Ministério da Sáude; processo licitatório n. 323/2005).

23 Para uma análise elucidativa e crítica do debate acerca da focalização e da universalização no campo da saúde pública, ver Cohn (2005). 


\section{REFERÊNCIAS BIBLIOGRÁFICAS}

Almeida-Filho, N. et al. 2004

Anand, S. S

Nov. 1999

Arretche, $M$.

2005

Azerêdo, Sandra 1994

Barbosa, M. I. 1988

Barrios, L. 2002

Bastos, F. I.; Travassos, $T$. 2005

Batista, L. E.; Kalckmann, S. 2005

Batista, L. E.; Escuder, M. M. L.; Pereira, J. C. R. 2004

Berquó, E. 1994

Boletim Instituto de Saúde dez. 2003

Caetano, A. J. 2004

Caldwell, $\mathrm{K}$. 2000

Cardoso, Fernando Henrique 1962

Carneiro, $\mathrm{S}$. 2002

Carneiro, S.; Santos, T. 1985

Carvalho, José Murilo 2000

Carvalho, José Murilo 2004

Chalhoub, S. 1996
Social Inequalities and depressive disorders in Bahia, Brazil: interactions of gender, ethnicity, and social class. Social Science $\mathcal{E}$ Medicine, v. 59 , p. $1339-53$

Using ethnicity as a classification variable in health research: perpetuating the myth of biological determinism, serving socio-political agendas, or making valuable contributions to medical sciences? Ethnicity $\mathcal{E}$ Health, v. 4, n. 4, p. 241-4.

A política da política de saúde no Brasil. In: Lima, N. T. et al. (org.) Saúde e democracia: história e perspectivas do Sistema Único de Saúde no Brasil. Rio de janeiro: Ed. Fiocruz, p. 285-306.

Teorizando sobre gênero e relações raciais.

Estudos Feministas, ano 2, n.e., p. 203-27.

Racismo e Saúde. Tese de Doutorado, Faculdade de Saúde Pública, Universidade de São Paulo.

III Conferência Mundial Contra o Racismo.

Estudos feministas, v. 1, p. 169-70.

'Raça' e Saúde Pública: os dilemas da ciência e da prática contemporânea. In: Minayo, M. C. S.; Coimbra Jr., C. E. A. (org.)

Críticas e atuantes: ciências sociais e humanas em saúde na América Latina. Rio de Janeiro: Ed. Fiocruz, p. 461-71.

Em busca de equidade no Sistema Único de Saúde.

In: Seminário - Saúde da população negra. São Paulo: Instituto de Saúde. p. 21-7.

A cor da morte: causas de óbito segundo características de raça no Estado de São Paulo, 1999 a 2001. Revista Saúde pública, v. 38, n. 5, p. 630-6.

Esterilização e raça em São Paulo.

Revista brasileira de estudos populacionais, v. 11, n. 1, p. 19-26.

Raça, etnia e saúde (n. 31).

A relação de cor da pele/raça e esterilização no Brasil: análise dos dados da pesquisa nacional sobre demografia e saúde - 1996. In: Monteiro, S.; Sansone, L. (org.) Etnicidade na América Latina: um debate sobre raça, saúde e direitos reprodutivos. Rio de Janeiro: Ed. Fiocruz. p. 229-49.

Fronteiras da diferença: raça e mulher no Brasil.

Estudos feministas, ano 8, n. 2, p. 91-108.

Capitalismo e escravidão no Brasil Meridional.

São Paulo: Difusão Européia do Livro.

A batalha de Durban.

Estudos feministas, n. 1, p. 209-14.

Mulher negra.

São Paulo: Nobel/Conselho Estadual da Condição Negra.

Cidadania na encruzilhada. In: Bignotto, Newton (org.) Pensar a República. Belo Horizonte: Ed. UFMG, p. 105-30.

Genocídio racial estatístico.

O Globo, 27.12.2004, p. 7.

Cidade febril.

São Paulo: Companhia das Letras. 
Chor, D. et al. 2004

Cohn, A. 2005

Cooper, L. A.; Hill, M. N.; Powe, N. R. 2002

Cooper, R. 2003

Corrêa, M. 1998

Diniz, D.; Guedes, C. 2003

Ellison, G. T.;

De Wet, $T$.

dec. 1997

Escorel, S.

1999

Ferreira, L. B.;

Pedrosa, M. A.;

Oliveira, S. F.

2003

Figueroa, A.

2004

Fiscella, K. et al. 2000

Fry, Peter $2004 a$

Fry, Peter $2004 b$

Fry, Peter 2005

Geronimus, A. 2000

Gershman, S. 1995

Gilroy, Paul 2000

Grin, M.

2001
Association of weight change with ethnicity and life course: socioeconomic position among Brazilian civil servants. International Journal of Epidemiology (UK), v. 33, n. 1, p. 100-6.

O SUS e o Direito à Saúde: universalização e focalização nas políticas de saúde. In: Lima, N. T.; Gershman S.; Edler, F.C.; Suárez, J.M. (orgs.) Saúde e Democracia: História e perspectivas do Sistema Único de Saúde no Brasil. Rio de Janeiro: Ed. Fiocruz, p. 385-405.

Designing and evaluating interventions to eliminate racial and ethnic

disparities in health care. Journal of General Internal Medicine, v. 17, p. 477-86.

Race, genes, and health: new wine in old bottles.

International Journal of Epidemiology, v. 32, p. 23-5.

As ilusões da liberdade: a Escola Nina Rodrigues e a antropologia no Brasil. Bragança Paulista: Edusf.

Educando para a genética: anemia falciforme e políticas de saúde no Brasil. Brasília: Letras Livres. (ANIS, 25)

The use of 'racial' categories in contemporary South African health research. A survey of articles published in the South African Medical Journal between 1992 and 1996. South African Medical Journal, v. 87, n. 12, p. 1671-9.

Reviravolta na Saúde: origem e articulação do Movimento Sanitário. Rio de Janeiro: Ed. Fiocruz.

Utilização do conceito de 'raça' nas ciências médicas.

Ciência e Saúde Coletiva. Livro de Resumos II do VII Congresso de Saúde Coletiva, 8 (supl. 2).

Contextualização conceitual e histórica. In: Seminário Nacional de Saúde da População Negra. Caderno de textos básicos.

Brasília: Seppir, Ministério da Saúde.

Inequality in quality: addressing socioeconomic, racial, and ethnic disparities in health care. Journal of the American Medical Association, v. 283 , n. 19 , p. $2579-84$.

As aparências que enganam: reflexões sobre 'raça' e saúde no Brasil. In: Monteiro, S.; Sansone, L. (org.) Etnicidade na América Latina: um debate sobre raça, saúde e direitos reprodutivos.

Rio de Janeiro: Ed. Fiocruz, p. 121-36.

Que aumento é esse?

O Globo, Opinião, 15.12.2004, p. 7.

A persistência da raça: ensaios antropológicos sobre o Brasil e a África austral. Rio de Janeiro: Civilização Brasileira.

To mitigate, resist, or undo: addressing structural influences on health of urban populations. American Journal of Public Health, v. 90, n. 6, p. 867-72.

A democracia inconclusa: um estudo da reforma sanitária brasileira. Rio de Janeiro: Ed. Fiocruz.

Against race: imagining political culture beyond the color line.

Cambridge: Harvard University Press.

Esse ainda obscuro objeto de desejo: políticas de ação afirmativa e ajustes normativos: o seminário de Brasília. Novos Estudos Cebrap, v. 59 , p. $172-92$. 
Grin, $M$.

$2004 a$

Grin, $M$. $2004 b$

Guimarães, A. S. A. 1999

Harell, J. P.; Hall, S.; 2003

Hasenbalg, C.;

Silva, Nelson do Valle 1988

Htun, $M$. 2004

Jaccoud, L.; Beghin, N. 2002

mar. 2001

Kaplan, J.; Bennet, T. 2003

Karter, A. 2003

Krieger, $\mathrm{N}$. 2003

Laguardia, J. 2004

Leal, M. C.;

Gama, S. G. N. G.;

Cunha, C. B. 2005

Lima, N. T. 2002

Lima, N. T.;

Hochman, G. 1996

Lima, N. T.;

Fonseca, C. M. O.;

Hochman, G. 2005

Lopes, A. 1997

Lopes, F. 2004
Políticas públicas e desigualdade racial: do dilema à ação.

In: Monteiro, S.; Sansone, L. (org.) Etnicidade na América Latina: um debate sobre raça, saúde e direitos reprodutivos.

Rio de Janeiro: Ed. Fiocruz. p. 331-44.

Auto-confrontação racial e opinião: o caso brasileiro e o norte-americano. Interseções, ano 6, n. 3, p. 95-120.

Racismo e anti-racismo no Brasil.

São Paulo: Ed. 34.

Physiological responses to racism and discrimination: an assessment of the evidence. American Journal of Public Health, v. 93, n. 2, p. 243-7.

Estrutura social, mobilidade e raça.

São Paulo: Vértice.

From 'racial democracy' to affirmative action: changing state policy on race in Brazil. Latin American Research Review, v. 39, n. 1, p.60-89.

Desigualdades raciais no Brasil: um balanço da intervenção governamental. Brasília: Ipea.

Jornal da RedeSaúde.Conferência Mundial contra o Racismo e Raça/Etnia, saúde e direitos reprodutivos, v. 23.

Use of race and ethnicity in biomedical publication.

Journal of the American Medical Association, v. 289, n. 20, p. 2709-16.

Commentary: race, genetics, and disease: in search of a middle ground. International Journal of Epidemiology, v. 32, p. 26-8.

Does racism harm health? Did child abuse exist before 1962 ?

On explicit questions, critical scene, and current controversies:

An ecosocial perspective. American Journal of Public Health, v. 93, n. 2, p. 194-9.

O uso da variável "raça" na pesquisa em saúde, Physis: revista de saúde coletiva, v. 14, n. 2, p. 197-232.

Desigualdades raciais, sócio-demográficas e na assistência pré-natal e ao parto, 1999-2001. Revista de Saúde Pública, v. 39, n. 1, p. 100-7.

O Brasil e a Organização Pan-Americana da Saúde: uma história de três dimensões. In: Finkelman, J. (org.) Caminhos da saúde pública no Brasil. Rio de Janeiro: Ed. Fiocruz/Opas/OMS, p. 25-116.

Condenado pela raça, absolvido pela medicina: o Brasil descoberto pelo Movimento Sanitarista da Primeira República. In: Maio, Marcos Chor; Santos, Ricardo Ventura (org.) Raça, ciência e sociedade. Rio de Janeiro: Ed. Fiocruz/CCBB, p. 23-40.

A saúde na construção do Estado Nacional no Brasil: Reforma sanitária em perspectiva histórica. In: Lima, N. T. et al. (org.) Saúde e democracia: história e perspectivas do Sistema Único de Saúde no Brasil.

Rio de janeiro: Ed. Fiocruz, p. 27-58.

Significado de raça em pesquisas médicas e epidemiológicas.

In: Barata, R. et al. (org.) Equidade e saúde: contribuições da epidemiologia. São Paulo, Rio de Janeiro: Abrasco, Ed. Fiocruz. p. 245-56.

Experiências desiguais ao nascer, viver, adoecer e morrer: tópicos em saúde da população negra. In: Seminário Nacional de Saúde da População Negra. Caderno de textos básicos.

Brasília: Seppir, Ministério da Saúde. 
Macedo, L. 2004

Maggie, Y.; Fry, P. 2004

Maio, Marcos Chor 2004

Maio, Marcos Chor 1999

Maio, Marcos Chor;

Santos, Ricardo Ventura 2005

Maio, Marcos Chor et al. 2005

Martins, R. 2004

McDermott, $R$ 1998

Ministério da Saúde (Brasil) 2001

Monteiro, Simone 2004

Monteiro, Simone; Maio, Marcos Chor 2005

Nazroo, J. 2003

Olinto, M. T.;

Olinto, B. A. 2000

Oliveira, F. 1999

Oliveira, F. 2002

Oliveira, G. C.;

Sant'anna, V. 2002

Paixão, $M$. 2005

Pena, S. D. P.;

Bortolini, M. C. 2004

Pierucci, F. 1999

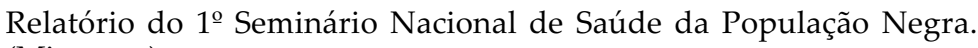
(Mimeogr.)

A reserva de vagas para negros nas universidades brasileiras. Estudos Avançados, v. 18, n. 50), p. 67-80.

Raça, doença e saúde pública no Brasil: um debate sobre o pensamento higienista do século XIX. In: Monteiro, S.; Sansone, L. (org.) Etnicidade na América Latina: um debate sobre raça, saúde e direitos reprodutivos. Rio de Janeiro: Ed. Fiocruz. p. 15-44.

O projeto Unesco e a agenda das ciências sociais nos anos 40 e 50. Revista Brasileira de Ciências Sociais, v. 14, n. 41, p. 141-58.

Política de cotas raciais, os 'olhos da sociedade' e os usos da antropologia: o caso do vestibular da Universidade de Brasília (UnB). Horizontes Antropológicos, n. 23, p. 181-214.

Cor/Raça no Estudo Pró-Saúde: resultados comparativos de dois métodos de auto-classificação no Rio de Janeiro. Cadernos de Saúde Pública, Fiocruz, v. 21, n. 1, p. 109-18.

Desigualdades raciais e políticas de inclusão racial: um sumário da experiência brasileira recente. Santiago: Cepal. (Série Políticas Sociales,82), 72 p.

Ethics, epidemiology and the thrifty gene: biological determinism as a health hazard. Social Science Medicine, v. 47, n. 9, p. 1189-95.

Manual de doenças mais importantes por razões étnicas da população brasileira afro-descendente. Brasília.

Desigualdades em saúde, raça e etnicidade: questões e desafios. In: Monteiro, S.; Sansone, L. (org.) Etnicidade na América Latina: um debate sobre raça, saúde e direitos reprodutivos. Rio de Janeiro: Ed. Fiocruz. p. 45-56.

Etnicidade, raça e saúde no Brasil: questões e desafios. In: Minayo, C.; Coimbra Jr., C. (org.) Críticas e atuantes: ciências sociais e saúde na América Latina. Rio de Janeiro: Ed. Fiocruz. p. 473-485.

The structuring of ethnic inequalities in health: economic position, racial discrimination, and racism. American Journal of Public Health. Feb., v. 93, n. 2, p. 277-84.

Raça e desigualdade entre as mulheres: um exemplo no sul do Brasil. Cadernos de Saúde Pública, v. 16, p. 1137-42.

O recorte racial/étnico e a saúde reprodutiva. In: Giffin, K.;

Costa, S. H. (ed.) Questões da saúde reprodutiva. Rio de Janeiro: Ed. Fiocruz.

Saúde da população negra.

Brasília: Opas/Seppir.

Chega de saudade, a realidade é que...

Estudos feministas, n. 1, p. 199-207.

Crítica da razão culturalista: relações raciais e a construção das desigualdades sociais no Brasil. Tese de Doutorado em Ciências Humanas/Sociologia. Rio de Janeiro, Iuperj.

Pode a genética definir quem deve se beneficiar das cotas universitárias e demais ações afirmativas? Estudos Avançados, v. 18, n. 50, p. 31-50.

Ciladas da diferença.

São Paulo: Ed. 34 
Pinto, P. G. H. R. 2005

Pinto, E. A.; Souza, R. 2002

Pnud; Opas 2001

Ribeiro, Matilde 1995

Risch, N. et al. 2002

Roland, E. 2001a

Roland, E. $2001 b$

Ryn, M. V.; Fu, S. S. 2003

Schwarcz, L. M. 1993

Silva, N. V. 1994

Souza, J. (ed.) 1997

Stepan, N. L. 1991

Tapper, M. 1999

Telles, E. 2003

Travassos, C.; 2004

Viana, A. L. A. (org.) 2001

Williams, D.; Neighbors, H.; Jackson, J. 2003

Wyatt, S. B. et al. 2003

Zago, M. A. 2004
Ação afirmativa, fronteiras raciais e identidades acadêmicas: uma etnografia das cotas para negros na Uerj. Trabalho apresentado na $1^{\text {a }}$ Conferência Internacional da Rede de Estudos de Ação Afirmativa, jan. Rio de Janeiro, UCAM, http://aasn.iuperj.br/Articles Paulo_Gabriel_Hilu.pdf (acessado em 7.6.2005.

Etnicidade e saúde da população negra no Brasil.

Cadernos de Saúde Pública, v. 18, n. 5, p.1144-5.

Política Nacional de Saúde da População Negra: uma questão de equidade. Brasília: Pnud, Opas, DFID.

Mulheres negras brasileiras: de Bertioga a Beijing. Estudos feministas, v. 3, n. 2, p.446-57.

Categorization of humans in biomedical research: genes, races and disease. Genome Biology, v. 3, n. 7, comment 2007.1-2007.12.

Saúde reprodutiva da população negra no Brasil: um campo em construção. Perspectivas em saúde e direitos reprodutivos, v. 2, n. 4, p. 17-23.

PAF: um programa que ainda não saiu do papel: entrevista com Edna Roland. Jornal da Rede Feminista de Saúde, n. 23. Disponível em: www.redesaude.org.br/jornal/html/body_jr23-edna.html,acesso em 15.8.2003.

Paved with good intentions: do public health and human service providers contribute to racial/ethnic disparities in health? American Journal of Public Health, v. 93, n. 2, p. 248-55.

O espetáculo das raças: cientistas, instituições e questão racial no Brasil 1870-1930. São Paulo: Companhia das Letras.

Uma nota sobre 'raça social' no Brasil.

Estudos afro-asiáticos, v. 26, p. 67-80.

Multiculturalismo e racismo: uma comparação Brasil - Estados Unidos.

Brasília: Paralelo 15.

The hour of eugenics: race, gender, and nation in Latin America.

Ithaca: Cornell University Press.

In the Blood: Sickle Cell Anemia and the Politics of Race.

Philadelphia: University of Pennsylvania Press.

Racismo à brasileira: uma nova perspectiva sociológica.

Rio de Janeiro: Relume-Dumará.

The concept and measurement of race and their relationship to public health: a review focused on Brazil and the United States.

Cadernos de saúde pública, v. 20, n. 3, p. 660-78, maio-jun.

A política de saúde no Brasil nos anos 90. Número temático do periódico Ciência $\mathcal{E}$ saúde coletiva, v. 6, n. 2.

Racial/Ethnic discrimination and health: findings from community Studies. American Journal of Public Health, v. 93, n. 2, p. 200-8.

Racism and cardiovascular disease in African Americans. The American Journal of The Medical Sciences, v. 325, n. 6, p. 315-31.

A pesquisa clínica no Brasil.

Ciência E saúde coletiva, v. 9, n. 2, p. 363-74. 